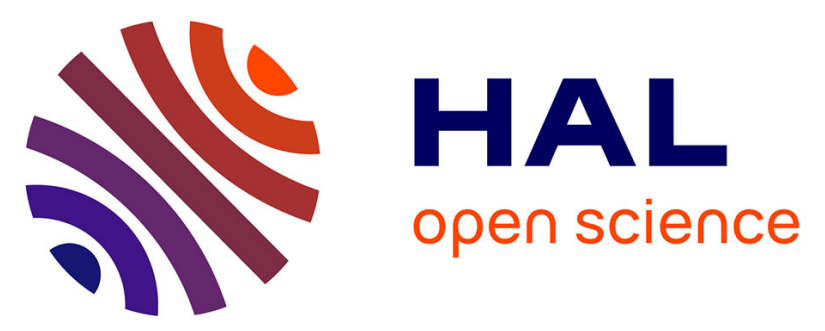

\title{
Possibilities and Benefits of Using Material Flow Information to Improve the Internal Hospital Supply Chain
}

Giuseppe Ismael Fragapane, Aili Biriita Bertnum, Jan Ola Strandhagen

\section{To cite this version:}

Giuseppe Ismael Fragapane, Aili Biriita Bertnum, Jan Ola Strandhagen. Possibilities and Benefits of Using Material Flow Information to Improve the Internal Hospital Supply Chain. IFIP International Conference on Advances in Production Management Systems (APMS), Sep 2019, Austin, TX, United States. pp.240-247, 10.1007/978-3-030-29996-5_28 . hal-02460497

\section{HAL Id: hal-02460497 https://hal.inria.fr/hal-02460497}

Submitted on 30 Jan 2020

HAL is a multi-disciplinary open access archive for the deposit and dissemination of scientific research documents, whether they are published or not. The documents may come from teaching and research institutions in France or abroad, or from public or private research centers.
L'archive ouverte pluridisciplinaire HAL, est destinée au dépôt et à la diffusion de documents scientifiques de niveau recherche, publiés ou non, émanant des établissements d'enseignement et de recherche français ou étrangers, des laboratoires publics ou privés.

\section{(c)(1)}

Distributed under a Creative Commons Attribution| 4.0 International License 


\title{
Possibilities and benefits of using material flow information to improve the internal hospital supply chain
}

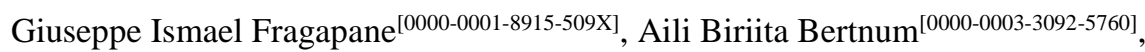 \\ Jan Ola Strandhagen ${ }^{[0000-0003-3741-9000]}$ \\ Department of Mechanical and Industrial Engineering, Norwegian University of Science and \\ Technology, 7491 Trondheim, Norway \\ \{giuseppe.fragapane, aili.b.bertnum, ola.strandhagen\}@ntnu.no
}

\begin{abstract}
The concept of Supply Chain Management has become increasingly important in healthcare and notably in hospitals. Information along the supply chain is the key element for analysis and improvement purposes. The aim of the study is to analyze and visualize the material flow at a Norwegian hospital to identify the possibilities and benefits in current and future planning and operation. The integration of IT enables combining material and information flow. Statically analyses of the material flow can support in planning and control of the logistics activities. The visualization of the material flow can support to take long-term decisions e.g. for distributing departments at the hospital.
\end{abstract}

Keywords: Material flow, Automated Guided Vehicle, Hospital

\section{Introduction}

The concept of Supply Chain Management (SCM) has become increasingly important in healthcare and notably in hospitals. The primary objective of SCM is "to integrate and manage the sourcing, flow, and control of materials using a total systems perspective across multiple functions and multiple tiers of suppliers" [1]. While literature concerning SCM on a strategic level is extensive, less academic literature focuses on tactical and operational challenges particular to the healthcare industry [2].

One of the key challenges and barriers for effective SCM in the healthcare industry is the lack of capital to build a sophisticated Information Technology (IT) infrastructure supporting supply chain operations [3]. Information along the supply chain is the key element for analysis and improvement purposes. In order to benchmark and measure performance improvements, it is important to define measures that track both material activities and related costs, and supply chain performance related to the core activity, patient care [2].

A recent literature review by Volland et al. [4] suggests that the availability of information across the supply chain can lead to more integrated supply chain concepts for hospitals. There is a need to understand how consistent IT systems and data standards across hospitals can improve the hospital supply chain. Several studies have shown that IT systems can improve purchasing decisions and reduce costs lowering inventory levels [5]. However, using SCM approaches in hospitals have proven to be more complex. The hospital supply chain has to manage a variety of product and service enterprises 
including medical consumables, pharmaceuticals, catering, laundry cleaning, waste management, home-care products, information technology, vehicle fleet management and general supplies [6]. Norwegian hospitals have started centralizing and automate both the external and especially the internal material flow [7, 8]. Consequently, the IT and automated transportation systems collect and align a large amount of information across the supply chain.

A previous study on internal logistics in a Norwegian hospital visualized the material and information flow in order to analyze the current situation of the supply chain [8]. Several IT and sharing systems are used and materials can be tracked and controlled throughout the internal supply chain. However, the IT and automated transportation systems create a huge amount of data, mainly for monitoring and controlling purposes. This data is often not further used or analyzed for improvement purposes and is typically known as 'idle data' [9]. Increased computing power has facilitated the possibilities of using data analytics to discover patterns and improvement possibilities from datasets where a human would not necessarily have found a pattern.

This study aims at answering the following questions: How can visualization of material flow information improve the internal supply chain of a hospital? Further, how can the hospital supply chain benefit from an integrated IT system? The study will be based on the data collection from the previous study at a Norwegian hospital further explained in section 3 .

The paper is structured as follows: Section 2 provides a background on related literature within hospital logistics and SCM. Section 3 presents an overview of the case hospital supply chain, followed by a description of the methodology. In section 4 , the results of the statistical analysis are presented, which are further discussed in section 5. This research will end with recommendations for further improvements for the case hospital and future research within this topic.

\section{Theoretical background}

Over the past 20 years, there has been an increase in healthcare expenditures in all OECD countries [10], which has motivated to improve the healthcare sector. A study by Poulin et al. [11] state that half of the logistics costs can be eliminated with efficient logistics management. Furthermore, Volland et al. [12] state that increasing logistics efficiency might not directly influence patient care but may give medical staff more time for patient related activities. It is important to recognize that logistics activities have an impact on the overall performance of the hospital [13].

Polater et al. [14] describe a hospital supply chain as "a complex system that requires the flow of products and services, in order to satisfy the needs of those who serve patients", with the aim to "deliver products at the right time, for the purpose of fulfilling the requirements of those providing healthcare". The hospital can be divided into an external and internal supply chain. The internal supply chain has to establish its own logistics network that correlates with external suppliers in order to supply the customer, in this case, the patient [15]. According to Volland et al. [12], the external supply chain has been received the most attention, while the internal supply chain is the weak spot in the hospital supply chain. Granlund \& Wiktorsson [13] argue that the performance 
of the internal supply chain highly affects the overall performance, and remark the importance of continuous improvement in order to achieve increased competitiveness.

The focus of internal logistics is to provide supplies to the company's core activities, which for hospitals is patient care. Logistics and material handling are described as an extensive and important part of the healthcare sector, but it is far from the sector's core competencies [13]. A high variety of materials is often required in a hospital, which usually leads to complex logistics activities. In addition, different departments are responsible for various procurement activities, e.g. food services are responsible for the food supply, while pharmacy services are responsible for managing the procurement of pharmaceuticals, etc. $[11,16]$, further increasing the complexity of SCM.

Introducing automation to logistics activities in the healthcare sector is viewed as a measure for improving efficiency and productivity [17]. The main challenges are knowledge transfer and adoption to technology, rather than the absence of available technology. Due to the complexity of the system, it is often difficult to establish central management and a consensus regarding the purpose of the system fitting all actors. It is crucial to distribute tasks and responsibilities appropriately, demonstrate the ability to have a comprehensive view on the planning process and to implement strategies and technologies on the basis of long-term benefits [13].

Several decisions and changes in hospitals have made the Automated Guided Vehicle (AGV) system a success and standard for material transportation in Norwegian hospitals. An AGV system can be defined as a driverless transportation system that is used for horizontal movement of materials, allowing for flexible material handling [18, 19]. Some of the advantages of implementing an AGV system are increased productivity and flexibility, cost efficiency, savings in labor costs, reduced emissions and energy consumption, and improved safety [20]. In general, success factors for the implementation of automation in hospitals include benchmarking, learning from other industries, involving hospital personnel, and identifying the internal logistics functions. Therefore, available data about hospital logistics is crucial. While there has been a strong interest in establishing patient data, data of material flow are still less used and analyzed.

The Nordic countries are leading in eHealth applications. The number of general practitioners using electronic health records is among the highest in Europe [21]. While it is well known that IT in healthcare and social services have the potential to improve the welfare and efficiency of systems, the potentials of IT technologies to improve hospital logistics are still scarcely explored in hospitals. According to Johns [22], Information and communication technology (ICT) is an important tool for increasing competitiveness in the healthcare industry. Furthermore, ICT can help for total integration of healthcare systems.

\section{$3 \quad$ Methodology}

This study has used the mixed methods approach, combining qualitative and quantitative methods in order to strengthen the credibility of the results. More precisely, the methodology used is triangulation being one of the most common mixed methods designs. It is described as "the use and combination of different methods to study the same 
phenomenon" [23] and aims to "validate quantitative statistical findings with qualitative data results" [24]. The research design consists of a case study and literature study. A literature study was conducted to establish the state-of-the-art on hospital supply chain, internal transportation in hospitals, and IT supporting hospitals. Observations and semi-structured interviews were performed to give an understanding of the case hospital and internal supply chain.

The case study was carried out in a large Norwegian hospital that has a capacity of 800 beds. The hospital implemented and launched an automated material handling system in 2009. Today, the automated material handling system consists of 21 AGVs, transporting approximately 50-70 tons of goods every week between 114 pick-up and delivery stations in different buildings, at different levels and departments. Daily, 500650 containers are transported by the AGV system. The AGV system is operated with a centralized structure.

A transportation schedule for the AGV system has been defined based on simulations, hospital layout, and battery management and maintenance. This schedule has been adapted to changing demand of goods over the years. Orders are dispatched to the nearest AGV. This dispatching rule was chosen to reduce AGV idle transportation time. The hospital has integrated a radio frequency communication system, connecting the different buildings, doors and elevators with the AGV system. The AGV can lift and move the wagons within the 4500-meter guide-path that connects all departments. AGVs can operate continuously for approximately three hours and is then sent to be charged for one hour.

Several individual and group interviews have been conducted with employees from both the operating and planning departments of the hospital. The positions of the interviewed hospital employees are Technical System Administrator, Supply Planner, Operating Manager, and Operating Technician. Based on the data received from the case hospital, a statistical analysis of the material transportation was conducted. The data represents the internal material transportation from October 2017 until March 2018.

\section{$4 \quad$ Analysis}

Based on the data retrieved from the AGV system of the case hospital, information about the material transportation were analysed to investigate the variety of transportation times and locations within the hospital. Fig 1 shows the average waiting and delivery times during the main hospital operation hours. During these hours, the following material groups are transported and supplied within the hospital: consumer and medical goods from both external suppliers and the central warehouse, waste, laundry, sterile goods, and food. 


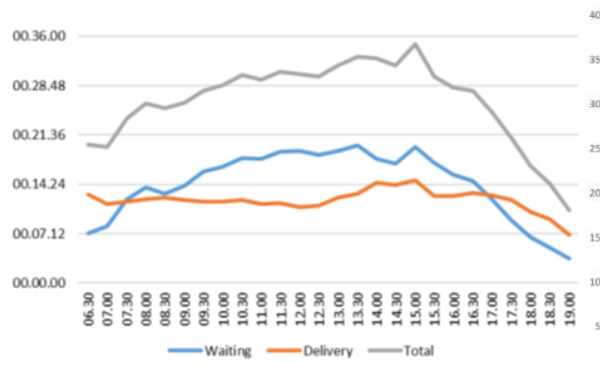

Fig. 1. AGV transportation time during an average day of operation.

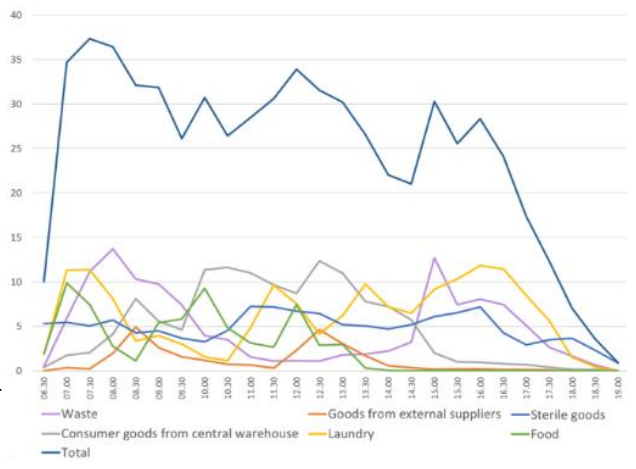

Fig. 2. Material groups transported and supplied within the case hospital during an average day

The pattern of transported goods is documented and clearly recognizable (see. Fig 2). Further, the material data provide insights about material supply during the different weekdays. The daily average amount of containers picked and delivered by the AGV at the different buildings within the hospital can be seen in Fig 4. Goods arrival and disposal is located in building 10 , and clearly represents the highest volume of hospital material movement. Building 2 follows where the kitchen, central sterilization service, and the emergency department are located. Laboratories and specialized departments of the hospital are located in the rest of the buildings, with a considerably lower volume of material movement.

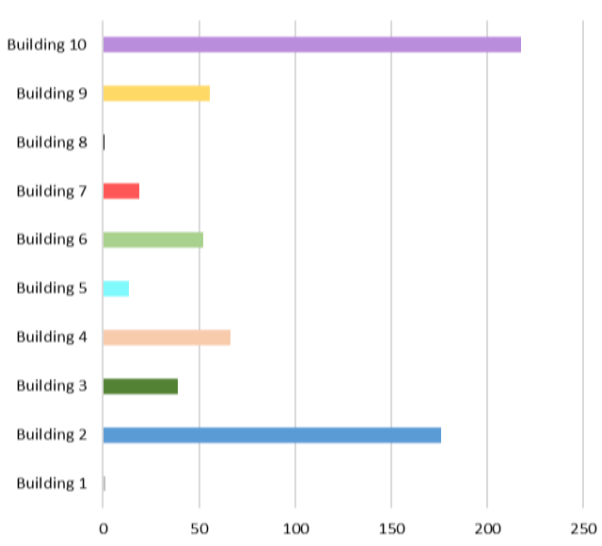

Fig. 3. Average amount of containers picked and delivered at the different buildings within the case hospital per day.

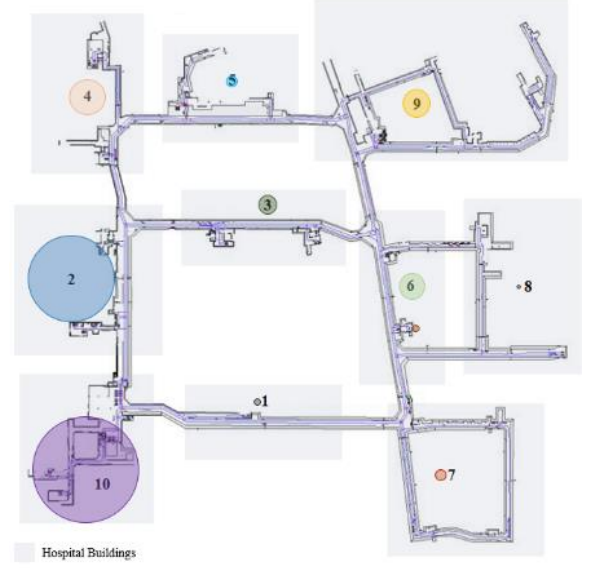

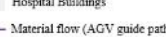

Fig. 4. Amount of containers picked and delivered, visualized in the case hospital layout. 


\section{$5 \quad$ Discussion and conclusion}

The hospital supply chain has high requirements for quality of services where timely delivery of materials is one of them. Lack of timely delivery of materials can have negative effects for a patient seeking treatment and care in a hospital. Sterile goods used in the operation departments must be delivered on time to ensure availability for any planned or acute medical operation. Patients need to receive their food within a certain time period in order to be ready for further operations or treatments.

The statistical analysis shows the transportation time of materials by AGVs in the case hospital. In general, the total transportation time varies throughout the day. While the average delivery time is rather stable, the waiting times are quite long at certain periods of the day. This can decrease the delivery precision of materials, which can lead to negative consequences for the patients. It can be argued that the waiting time is influenced by both transportation volume and AGV capacity in the specific periods. Balancing the transportation volume or combining deliveries to reduce the transportation volume are possible approaches for achieving timely delivery. This is possible since materials and respectively material groups transported and supplied during the operation hours of the case hospital varies strongly.

Changing the timely supply of materials can have critical consequences in hospitals. According to Abdulsalam et al. [25], the healthcare supply chain is more fragile on critical supplies compared to other industries. Some materials and products must always be available in case of an emergency. It can be critical or fatal if the patient cannot receive instantly treatment due to missing supplies. Even though customization is an increasing trend in most industries, some supplies in the hospital supply chain are highly customized and are one-of-kind products for one certain patient [26, 27]. Often are a large number of actors involved in the hospital supply chain with different interests when supplying materials or products [25]. Thus, the hospital supply chain can be described as highly fragmented, which can prevent from operating as a system [28].

In general, not all materials moved within hospitals can be captured by the ICT system. Centralizing the material flow with the AGV system in a hospital can support to link the information along the supply chain and visualize the main material movements. The statistical analysis and the visualization of the material flow within the case hospital provide new opportunities to improve the timely delivery of materials and the performance of the internal hospital supply chain. Information derived from the statistical analysis supports the identification of material groups that can rather be moved outside of the overloaded operation hours.

The traceability and tracking of materials within the case hospital have been demonstrated in a previous study [8]. The integration of IT technologies in hospitals enables to combine the material and information flow along the supply chain and therefore to identify critical products. These measures help to identify and decide whether products can be transported in a different period or not. Visualizing the material flow in hospitals can support decision-makers in scheduling the material flow on a tactical level to balance the internal material flow to increase the timely delivery of materials. In the case hospital, the material traffic is strongly one-sided distributed. 
The current policy in several countries is to expand larger hospitals and restructure them, and simultaneously close smaller hospitals [29]. The insights of the material flow information can support in deciding where to place new departments or where to move current departments. Decisions on centralizing or decentralizing, insourcing or outsourcing departments or inventories, and changing the time period of internal material supply can also be based on a statistical analysis of material flow. Future research should focus on how to link information both material flow and electronic health records to further improve decision-making and performance of hospitals. Thus, electronic health records can be integrated and be input for forecasting and planning the material flow.

\section{Acknowledgement}

This research received funding from the strategic research area NTNU Health in 2018 at NTNU, Norwegian University of Science and Technology. The authors also gratefully acknowledge the case hospital that made it possible to carry out this study.

\section{References}

1. Monczka, R.M., et al., Purchasing and supply chain management. 2015: Cengage Learning.

2. McKone-Sweet, K.E., P. Hamilton, and S.B. Willis, The ailing healthcare supply chain: $a$ prescription for change. Journal of Supply Chain Management, 2005. 41(1): p. 4-17.

3. Burns, L.R., The health care value chain: producers, purchasers, and providers. 2002: Jossey-Bass San Francisco.

4. Volland, J., et al., Material logistics in hospitals: a literature review. Omega, 2017. 69: p. 82-101.

5. Kumar, S., R.A. DeGroot, and D. Choe, Rx for smart hospital purchasing decisions: The impact of package design within US hospital supply chain. International Journal of Physical Distribution \& Logistics Management, 2008. 38(8): p. 601-615.

6. Gattorna, Strategic supply chain alignment: Best practice in supply chain management. Gower Publishing Company, 1998.

7. Ullrich, G., Automated guided vehicle systems. Springer-Verlag Berlin Heidelberg. doi, 2015. 10: p. 978-3.

8. Fragapane, G.I., et al., Material Distribution and Transportation in a Norwegian Hospital: A Case Study IFAC INCOM 2018, 16th IFAC Symposium on Information Control Problems in Manufacturing, Bergamo, Italy, in-press.

9. Schmidt, R., et al., Industry 4.0 - Potentials for Creating Smart Products: Empirical Research Results, in International Conference on Business Information Systems. 2015: Poznań, Poland. p. 16-27.

10. OECD, Fiscal Sustainability of Health Systems. 2015.

11. Poulin, É., Benchmarking the hospital logistics process. CMA Management, 2003. 77(1): p. 20 .

12. Volland, J., et al., Material logistics in hospitals: A literature review. Elsevier, 2017. Omega 69 p. 82-101. 
13. Granlund, A. and M. Wiktorsson, Automation in Internal Logistics: Strategic and Operational Challenges. Vol. 18. 2014. 538-558.

14. Polater, A., C. Bektas, and S. Demirdogen. An investigation of government and private hospitals' supply chain management. in 2014 International Conference on Advanced Logistics and Transport (ICALT). 2014.

15. Rivard-Royer, H., S. Landry, and M. Beaulieu, Hybrid stockless: a case study: Lessons for health-care supply chain integration. International Journal of Operations \& Production Management, 2002. 22(4): p. 412-424.

16. Ozkil, A.G., et al. Service robots for hospitals: A case study of transportation tasks in a hospital. in 2009 IEEE International Conference on Automation and Logistics. 2009.

17. Bačík, J., et al., Pathfinder-Development of Automated Guided Vehicle for Hospital Logistics. IEEE Access, 2017. 5: p. 26892-26900.

18. Vis, I.F.A., Survey of research in the design and control of automated guided vehicle systems. European Journal of Operational Research, 2006. 170(3): p. 677-709.

19. Mehrabian, A., R. Tavakkoli-Moghaddam, and K. Khalili-Damaghani, Multi-objective routing and scheduling in flexible manufacturing systems under uncertainty. Iranian Journal of Fuzzy Systems, 2017. 14(2): p. 45-77.

20. Bechtsis, D., et al., Sustainable supply chain management in the digitalisation era: The impact of Automated Guided Vehicles. Journal of Cleaner Production, 2017. 142: p. 39703984.

21. Bergstrøm, R. and V. Heimly, Information technology strategies for health and social care in Norway. International journal of circumpolar health, 2004. 63(4): p. 336-348.

22. Johns, P.M., Integrating information systems and health care. Logistics Information Management, 1997. 10(4): p. 140-145.

23. Chris, V., T. Nikos, and F. Mark, Case research in operations management. International Journal of Operations \& Production Management, 2002. 22(2): p. 195-219.

24. Hesse-Biber, S.N., Mixed Method Research - Merging Theory with Practice. 2010, New York, USA: The Guilford Press.

25. Abdulsalam, Y., et al., Health Care Matters: Supply Chains In and Of the Health Sector. Journal of Business Logistics, 2015. 36(4): p. 335-339.

26. Dobrzykowski, D., et al., A structured analysis of operations and supply chain management research in healthcare (1982-2011). International Journal of Production Economics, 2014. 147: p. 514-530.

27. Rimpiläinen, T.I. and H. Koivo. Modeling and Simulation of Hospital Material Flows. in Tenth International Conference on Computer Modeling and Simulation (uksim 2008). 2008.

28. Rimpiläinen, T.I. and H. Koivo. Modeling and Simulation of Hospital Material Flows. in Computer Modeling and Simulation, 2008. UKSIM 2008. Tenth International Conference on. 2008. IEEE.

29. Giancotti, M., A. Guglielmo, and M. Mauro, Efficiency and optimal size of hospitals: Results of a systematic search. PloS one, 2017. 12(3): p. e0174533. 